\title{
Vulnerability to rumours during the COVID-19 pandemic in Singapore
}

\author{
Victoria JE $\underline{\text { Long, }}{ }^{1} M P H$, Wei Shien $\underline{\text { Koh }},{ }_{B S}^{1}$, Young Ern $\underline{\text { Saw }},{ }_{B A}^{2}$, Jean CJ $\underline{\operatorname{Liu}},{ }^{1,2}{ }_{P h D}$
}

\begin{abstract}
Introduction: Amid the COVID-19 pandemic, many rumours have emerged. Given prior research linking rumour exposure to mental well-being, we conducted a nationwide survey to document the base rate of rumour exposure and factors associated with rumour vulnerability.

Methods: Between March and July 2020, 1,237 participants were surveyed on 5 widely disseminated COVID-19 rumours (drinking water frequently could be preventive, eating garlic could be preventive, the outbreak arose because of bat soup consumption, the virus was created in an American lab, and the virus was created in a Chinese lab). For each rumour, participants reported whether they had heard, shared or believed each rumour.

Results: Although most participants had been exposed to COVID-19 rumours, few shared or believed these. Sharing behaviours sometimes occurred in the absence of belief; however, education emerged as a protective factor for both sharing and belief.

Conclusion: Our results suggest that campaigns targeting skills associated with higher education (e.g. epistemology) may prove more effective than counter-rumour messages.
\end{abstract}

Ann Acad Med Singap 2021;50:232-40

Keywords: Fake news, infectious diseases, infodemic, misinformation, public health, social media

\section{INTRODUCTION}

The global outbreak of coronavirus disease 2019 (COVID-19) has come with increased psychological burden. In several meta-analyses, depression and anxiety symptoms have been found to be elevated among healthcare workers and the general population. ${ }^{1-3}$ Others have reported a higher incidence of stress-related symptoms or post-traumatic stress disorder. ${ }^{4,5}$ These findings highlight the urgent need to understand factors predicting anxiety and mood outcomes, allowing vulnerable individuals to be identified and interventions to be developed.

In terms of predictors, exposure to COVID-19 rumours has emerged as a risk factor for poor mental health. ${ }^{6-9}$ This negative mental health impact has occurred against the backdrop of an "infodemic"-a surge of COVID-19 misinformation created and shared primarily via social media. ${ }^{10}$ In particular, the fastchanging nature of the pandemic means that accurate information has not always been accessible, resulting in many uncertainties. ${ }^{11,12}$ This has given rise to a large number of rumours. ${ }^{13,14}$

To date, several publications have used publicly available data to analyse and document the spread of rumours. For example, during the early stage of the pandemic (December 2019 to April 2020), search engine keywords reflected popular myths, ${ }^{15,16}$ with a large number of searches pertaining to alternative medicines that had been speculated to prevent COVID-19 (e.g. garlic, Chinese medicinal herbs or the malaria medication chloroquine). ${ }^{12}$ On social media platform Twitter, conspiratorial theories were posted regarding disease origins, suggesting for example that the virus had been developed as a bioweapon or had resulted from the introduction of $5 \mathrm{G}$ mobile networks. ${ }^{17,18}$

In turn, the spread of COVID-19 rumours has led to deleterious consequences. In Iran for example, a myth that alcohol consumption could prevent or treat COVID-19 resulted in over 700 deaths related to methanol poisoning, with deaths from methanol

\footnotetext{
${ }^{1}$ Duke-NUS Medical School, Singapore

${ }^{2}$ Division of Social Sciences, Yale-NUS College, Singapore

Correspondence: Dr Jean CJ Liu, Division of Social Sciences, Yale-NUS College, 28 College Ave West, Singapore 169857

Email: jeanliu@yale-nus.edu.sg
} 


\section{CLINICAL IMPACT}

\section{What is New}

- Most participants had been exposed to rumours, and confessed to sharing them even when they do not believe this information.

- Participants with higher education levels receive more rumours, but were less likely to believe or share them.

\section{Clinical Implications}

- The spread of health misinformation can undermine public health campaigns.

- As rumours are shared even when individuals do not believe them, providing fact-checking information may not be enough to stem the spread of rumours.

- Strategies to target education or individual vulnerabilities may be more effective.

poisoning exceeding those attributed to COVID-19 in some provinces. ${ }^{19}$ Returning to mental health outcomes, the extent to which an individual has been exposed to, has shared, or believed in COVID-19 rumours has also been found to predict anxiety symptoms. ${ }^{7}$

While demographic predictors of pandemic-related mental health are difficult to address (e.g. age, gender, pre-existing medical conditions), ${ }^{5}$ a person's exposure to rumours may constitute a modifiable risk factor. ${ }^{20-22}$ Correspondingly, efforts to develop interventions would benefit from an understanding of rumour vulnerability: the base rates by which individuals are exposed to, believe in, or share rumours; and factors predicting these rumour-related experiences. ${ }^{23}$

At present, little is known about individual vulnerability to COVID-19 rumours. While a handful of studies have surveyed individuals on their social media usage and enquired about rumour dissemination via these platforms, ${ }^{24}$ we are not aware of any study that has identified persons most likely to encounter, believe in, or to share COVID-19 rumours. To address this gap in the literature, we thus conducted a nationwide survey examining rumour vulnerability during the COVID-19 pandemic.

\section{METHODS}

\section{Study design and population}

Our study was conducted from 7 March to 27 July 2020 in Singapore, which had a high number of COVID-19 cases in the early stage of the pandemic. During this time, we recruited 1,237 participants who met the following eligibility criteria: aged $\geq 21$ years old, and had lived in Singapore for $\geq 2$ years. All participants were recruited via social media advertisements within community groups (e.g. groups for residential estates, universities and workplaces), or through paid Facebook advertisements targeting Singapore-based users.

Upon study enrolment, participants provided informed consent and completed a 20-minute online survey via Qualtrics. As part of a larger study, participants reported their: demographics, responses to the pandemic, sources of COVID-19 news, and (as we report in this paper) familiarity with rumours. ${ }^{7,25,26}$ The study protocol was approved by the Yale-NUS College Ethics Review Committee (Ethics Approval Number: 2020-CERC-001) and was pre-registered on ClinicalTrials.gov (NCT04305574).

\section{Outcome variables}

As the primary outcome variables, we assessed participants' familiarity with 5 rumours that had been widely spread during the COVID-19 pandemic: (1) drinking water frequently will help prevent infection (COVID-19 prevention); (2) eating garlic can help prevent infection (COVID-19 prevention); (3) the outbreak arose from people eating bat soup (COVID-19 origins); (4) the virus was created in a US lab to affect China's economy (COVID-19 origins); and (5) the virus was created in a Chinese lab as a bioweapon (COVID-19 origins). These rumours were presented in the survey as claims, rather than rumours to avoid influencing participants' response. Rumours were selected for their widespread distribution both internationally and within the local context.

For each rumour, participants indicated whether they: (1) had heard the claim before (yes/no); (2) thought the claim was true (yes/no); or (3) had shared the claim on social media such as Facebook and WhatsApp (yes/ no). We assigned a score of 1 for "yes" responses, and summed across the rumours to create 3 scores: the total number of claims heard, the total number of claims believed, and the total number of claims shared. Finally, participants also indicated which of 13 possible sources they had encountered the rumours (e.g. Facebook, WhatsApp, online forums, television, etc.).

\section{Predictor variables}

As predictor variables, participants reported the following demographic details: age, gender, ethnicity, religion, country of birth, marital status, education, house type (a proxy of socio-economic status), and household size. 
Using the survey timestamp, we also recorded two situation-related variables: the total number of local cases reported to date, and whether the country had been in a lockdown when participants completed the survey.

\section{Statistical analysis}

Using counts (\%), we first summarised the baseline rates of rumour familiarity and rumour sources. As further exploratory analyses, we conducted Fisher's exact test to explore the relationship between believing and sharing each rumour.

We then ran linear regression models to predict the following outcome measures: the total number of claims heard (Model 1), the total number of claims shared (Model 2), and the total number of claims believed (Model 3). Each model involved the full set of predictor variables described before, with the number of COVID-19 cases log-transformed for linearity.

For each model, we applied Bonferroni correction to control the type 1 family-wise error rate at 0.05 (Bonferroni-adjusted alpha level of $0.05 / 22$ predictors $=0.002)$. All statistical analyses were conducted using $\mathrm{R}$ version 4.0.

\section{RESULTS}

\section{Response rate}

Out of 1,751 individuals who accessed the survey link, 1,446 (82.6\%) provided informed consent and participated in the survey. However, 209 (14.5\%) participants did not complete the primary outcome measures (on COVID-19 rumours) and were excluded from statistical analyses.

The final sample of 1,237 participants is comparable to the resident population with regards to: the proportion of participants born in Singapore, ethnicity, household size and age ( $\leq 10 \%$ difference) However, our sample had more participants who were female $(63.9 \%$ versus $51.1 \%$ ), single ( $41.9 \%$ vs $18.8 \%$ ), and university graduates ( $70.7 \%$ vs $32.4 \%$ ); and fewer participants who lived in 1 -3-room public housing flats $(8.2 \%$ vs $23.7 \%)$ or who had Buddhist beliefs (14.6\% vs 33.2\%) (Table 1).

\section{Base rates of familiarity with COVID-19 rumours}

Out of 5 widely disseminated rumours, the average participant had heard of $3.34(\mathrm{SD}=1.33)$ rumours. The most commonly heard rumour, reported by 8 in 10 participants $(84.6 \%)$, was that the outbreak had arisen from individuals eating bat soup. Despite high exposure to COVID-19 rumours, however, participants only believed an average of 0.27 claims $(\mathrm{SD}=0.59)$ and shared $0.18(\mathrm{SD}=0.63)$. The most commonly believed rumour was that drinking water could prevent infection (11.4\%), whereas the most commonly shared rumour was that the disease had arisen from bat soup consumption (7.1\%) (Fig. 1).

In other words, most participants who had heard each of the 5 rumours neither believed nor shared the claims. Using Fisher's exact test, we conducted exploratory analyses to examine how belief and sharing behaviours were related. First, for the claim about the US manufacturing the coronavirus to affect China's economy, none who shared this rumour believed that it was true ( $P$ value of 1 for Fisher's exact test). In the case of the other 4 rumours, however, there was a significant association between belief and sharing $(P<0.001$ for the rumours on drinking water and bat soup; $P=0.001$ for the rumour on garlic; and $P=0.02$ for the rumour on China creating the virus). Nonetheless, even with these 4 rumours, not all who propagated the rumours believed that they were true (Fig. 2).

Finally, Fig. 3 depicts how participants had encountered COVID-19 rumours. As has been previously reported, ${ }^{27,28}$ social media platforms emerged as the leading sources, with 1 in 2 individuals reporting exposure through Facebook (55.5\%) or WhatsApp (53.6\%).

\section{Predicting rumour hearing, sharing and believing}

Model 1 examined if any demographic or situational factors predicted the number of rumours heard. As shown in Table 2, participants reported hearing more rumours when confirmed local cases were few (early in the pandemic) (beta $[b]=-0.621, t(1190)=-3.588$, $P<0.001)$ or as lockdown restrictions were lifted $(b=1.129, t(1190)=4.289, P<0.001)$. Additionally, there was a trend for education to predict rumour exposure, with those with higher education hearing more rumours $(b=0.077, t(1190)=2.625, P=0.009)$. However, this association was not observed with Bonferroni correction.

In Models 2 and 3, the same set of predictors were used to predict the number of rumours shared and believed, respectively. For both these models, those who were more educated shared or believed fewer rumours (Model 2: $b=-0.046, t(1190)=-3.289, P=0.001 ;$ Model $3: b=-0.046$, $t(1190)=-3.488, P=0.001)$.

\section{DISCUSSION}

During times of crisis, rumours have the potential to transmit misinformation and induce anxiety. ${ }^{29,30}$ Against the backdrop of the COVID-19 pandemic, we thus documented how individuals in the community 
Table 1. Baseline demographics of participants

\begin{tabular}{|c|c|c|}
\hline Characteristic & $\mathbf{n}$ & $(\%)$ \\
\hline \multicolumn{3}{|l|}{ Age $($ Mean $=39.3, \mathrm{SD}=12.7)$} \\
\hline \multicolumn{3}{|l|}{ Gender } \\
\hline Female & 791 & $(63.9)$ \\
\hline Male & 445 & $(36.0)$ \\
\hline Did not answer & 1 & $(0.1)$ \\
\hline \multicolumn{3}{|l|}{ Ethnicity } \\
\hline Chinese & 1047 & $(84.6)$ \\
\hline Indian & 55 & $(4.4)$ \\
\hline Malay & 71 & $(5.7)$ \\
\hline Others & 63 & $(5.1)$ \\
\hline Did not answer & 1 & $(0.1)$ \\
\hline \multicolumn{3}{|l|}{ Religion } \\
\hline Buddhism & 181 & $(14.6)$ \\
\hline Taoism/ Chinese traditional beliefs & 51 & $(4.1)$ \\
\hline Islam & 71 & $(5.7)$ \\
\hline Hinduism & 41 & $(3.3)$ \\
\hline Roman Catholicism & 125 & $(10.1)$ \\
\hline Christianity (Protestant) & 405 & $(32.7)$ \\
\hline No religion & 331 & $(26.7)$ \\
\hline Others & 30 & $(2.4)$ \\
\hline Did not answer & 2 & $(0.2)$ \\
\hline \multicolumn{3}{|l|}{ Married status } \\
\hline Single & 518 & $(41.9)$ \\
\hline Married & 667 & $(53.9)$ \\
\hline Widowed/ separated/ divorced & 47 & $(3.8)$ \\
\hline Did not answer & 5 & $(0.4)$ \\
\hline \multicolumn{3}{|l|}{ Educational level } \\
\hline Primary school & 4 & $(0.3)$ \\
\hline Secondary school & 65 & $(5.3)$ \\
\hline Junior college & 91 & $(7.4)$ \\
\hline Vocational training & 22 & $(1.8)$ \\
\hline Polytechnic/ diploma & 154 & $(12.4)$ \\
\hline University (undergraduate) & 623 & $(50.3)$ \\
\hline University (postgraduate) & 252 & $(20.4)$ \\
\hline Did not answer & 26 & $(2.1)$ \\
\hline
\end{tabular}

Table 1. Baseline demographics of participants (Cont'd)

\begin{tabular}{|c|c|c|}
\hline Characteristic & $\mathbf{n}$ & $(\%)$ \\
\hline \multicolumn{3}{|l|}{ House type } \\
\hline HDB flat: $1-2$ rooms & 12 & $(1.0)$ \\
\hline HDB flat: 3 rooms & 89 & $(7.2)$ \\
\hline HDB flat: 4 rooms & 305 & $(24.6)$ \\
\hline HDB flat: 5 rooms or executive flats & 358 & $(28.9)$ \\
\hline Condominium or private apartments & 321 & $(25.9)$ \\
\hline Landed property & 131 & $(10.6)$ \\
\hline Did not answer & 21 & $(1.7)$ \\
\hline \multicolumn{3}{|l|}{ Household size } \\
\hline 1 & 55 & $(4.4)$ \\
\hline 2 & 178 & $(14.4)$ \\
\hline 3 & 279 & $(22.6)$ \\
\hline 4 & 359 & $(29.0)$ \\
\hline $5+$ & 364 & $(29.4)$ \\
\hline Did not answer & 2 & $(0.2)$ \\
\hline \multicolumn{3}{|l|}{ Country of birth } \\
\hline Singapore & 1004 & $(81.1)$ \\
\hline Others & 232 & $(18.8)$ \\
\hline Did not answer & 1 & $(0.1)$ \\
\hline
\end{tabular}

were vulnerable to receive, believe in, or share specific COVID-19 rumours.

First, we observed that rumour exposure was endemic. Nearly all participants had heard at least one rumour and were familiar with an average of 3 out of 5 popular claims assessed. Additionally, most rumour transmission occurred via social media channels (e.g. Facebook and WhatsApp), as others have noted. ${ }^{31,32}$

Extending previous research, we further described how the base rate of believing or sharing rumours was far lower than the rate of exposure (with an average of $<1$ rumour believed or shared). Notably, belief and sharing behaviours did not always co-occur. In the extreme case of one rumour in particular (that the COVID-19 crisis had been manufactured by the US), not a single participant who reported forwarding the rumour actually believed in it. Although belief and sharing were linked for the other rumours we assessed, there continued to be individuals who shared rumours without believing their veracity. 


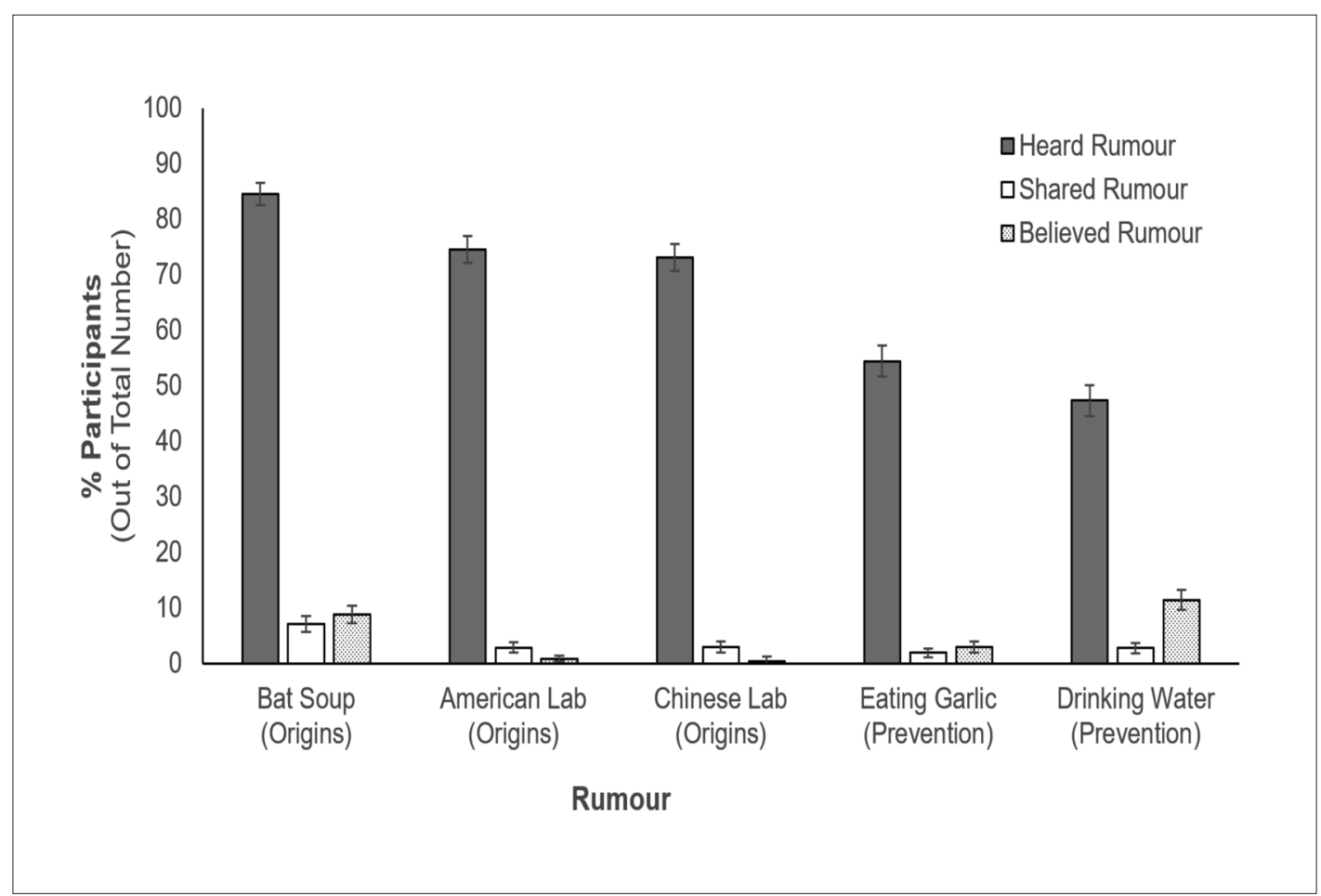

Fig. 1. Proportion of participants hearing, sharing and believing each COVID-19 rumour (that the virus originated from the consumption of bat soup, from an American lab, or from a Chinese lab; or that the virus can be cured by eating garlic or drinking water). Vertical lines represent the $95 \%$ confidence interval.

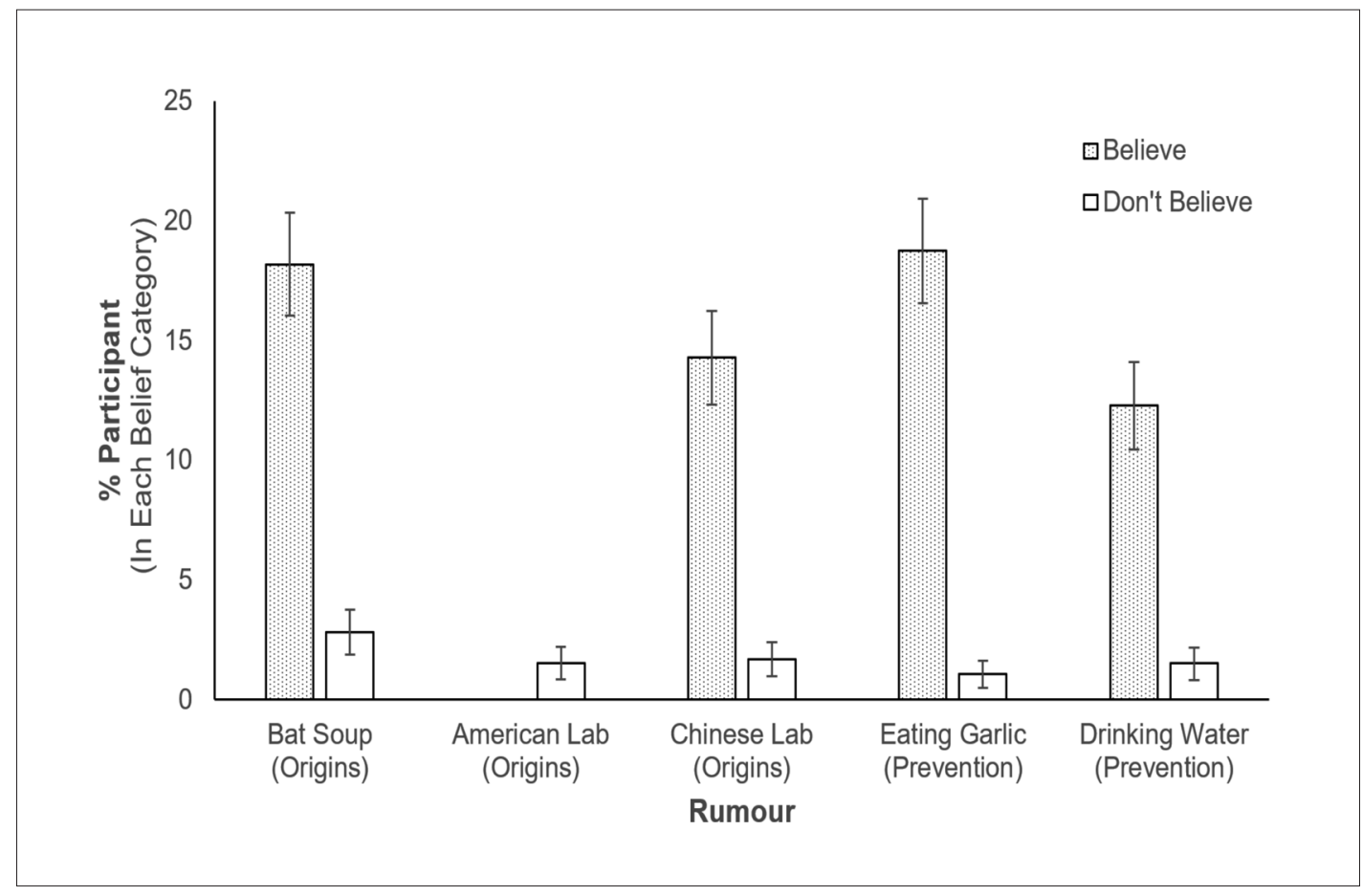

Fig. 2. For each rumour, the vertical bar depicts the number of participants who shared each rumour, represented as a percentage of participants who believed or disbelieved each rumour. Vertical lines represent the $95 \%$ confidence interval. 


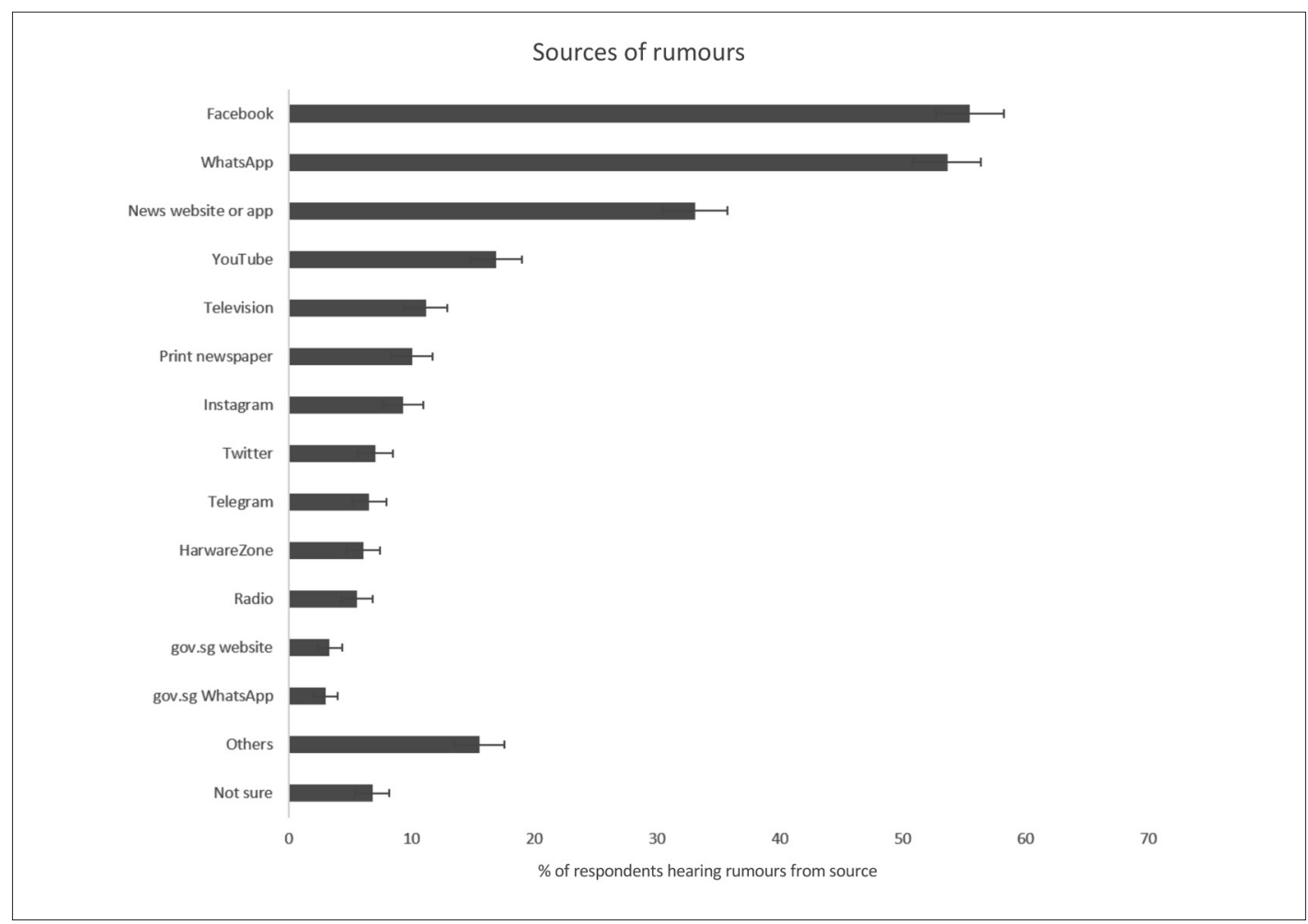

Fig. 3. Sources of where participants heard COVID-19 rumours. Horizontal lines represent 95\% confidence interval.

Our finding that COVID-19 rumours were disseminated even when disbelieved highlights the sheer difficulty of managing the so-called "infodemic". Although similar findings had been reported outside the COVID-19 context, ${ }^{33}$ the World Health Organization and individual governments continue to issue fact-checking statements as the prevailing strategy to debunk rumours..$^{34,35}$ Our results bring to question the utility of such statements, since individuals continue to share claims despite perceiving them to be untrue.

Based on our findings, an alternative strategy might be to target individual vulnerabilities instead of rumour content. This draws on previous findings suggesting that COVID-19 information-seeking differs across demographic groups. ${ }^{36,37}$ In our context, given that rumour exposure changed with pandemic severity (e.g. the number of cases) and most individuals had encountered COVID-19 rumours, the ensuing question is why only certain individuals fell prey to such rumours. Here, we found that educational level was a consistent predictor of vulnerability: although higher education predicted that an individual would hear more rumours, higher education was nonetheless protective, associated with fewer rumours shared or believed. Consequently, it may be advantageous to increase public awareness of knowledge and skillsets associated with higher education, such as epistemology or scientific thinking. ${ }^{33,38} \mathrm{We}$ note, however, that the correlational nature of our dataset precludes causal inferences, and further research will be needed to examine the efficacy of such strategies in curbing pandemic-related rumours.

\section{Limitations}

In describing these findings, we highlight several limitations of our research methods. First, we relied on participants' self-reports regarding rumour exposure and behaviours. Although this strategy provided individual-level information (such as beliefs and demographics) not available in studies of actual rumour posts (e.g. when Twitter posts are mined), the survey method is vulnerable to recollection and reporting biases. Moving forward, future studies may opt to integrate digital documentation of rumour posts alongside self-reported measures.

As a second limitation, we only sampled rumours that were not time-sensitive. Given the limitations of the survey methodology, we could not track rumours that arose from fast-changing events on the ground (e.g. rumours about the first COVID-19-related death in Singapore, rumours about the availability of face masks). It thus remains to be seen whether our findings can be generalised to these forms of rumours. 
Table 2. Predicting the number of rumours, heard, shared and believed during the COVID-19 outbreak

\begin{tabular}{|c|c|c|c|c|c|c|}
\hline \multirow[b]{3}{*}{ Age } & \multicolumn{6}{|c|}{ Outcome Measure $^{a}$} \\
\hline & \multicolumn{2}{|c|}{$\begin{array}{l}\text { Model 1: Number of } \\
\text { rumours heard }\end{array}$} & \multicolumn{2}{|c|}{$\begin{array}{l}\text { Model 2: Number of } \\
\text { rumours shared }\end{array}$} & \multicolumn{2}{|c|}{$\begin{array}{l}\text { Model 3: Number of } \\
\text { rumours believed }\end{array}$} \\
\hline & 0.003 & $(0.004)$ & 0.005 & $(0.002)$ & 0.002 & $(0.002)$ \\
\hline \multicolumn{7}{|l|}{$\begin{array}{l}\text { Gender } \\
\text { (base = Female) }\end{array}$} \\
\hline Male & -0.084 & $(0.080)$ & -0.025 & $(0.038)$ & 0.017 & $(0.036)$ \\
\hline \multicolumn{7}{|l|}{$\begin{array}{l}\text { Ethnicity } \\
\text { (base = Chinese) }\end{array}$} \\
\hline Indian & -0.456 & $(0.353)$ & -0.060 & $(0.169)$ & 0.152 & $(0.159)$ \\
\hline Malay & -0.537 & $(0.279)$ & 0.349 & $(0.133)$ & 0.184 & $(0.125)$ \\
\hline \multicolumn{7}{|l|}{$\begin{array}{l}\text { Religion } \\
\text { (base }=\text { No religion) }\end{array}$} \\
\hline Christianity (Protestant) & 0.093 & $(0.101)$ & -0.018 & $(0.048)$ & 0.012 & $(0.045)$ \\
\hline Buddhism & 0.159 & $(0.125)$ & 0.115 & $(0.060)$ & -0.025 & $(0.056)$ \\
\hline Roman Catholicism & 0.115 & $(0.144)$ & 0.036 & $(0.069)$ & 0.135 & $(0.065)$ \\
\hline Taoism/ Chinese traditional beliefs & 0.171 & $(0.207)$ & 0.018 & $(0.099)$ & 0.078 & $(0.093)$ \\
\hline Islam & 0.330 & $(0.325)$ & 0.006 & $(0.155)$ & -0.104 & $(0.146)$ \\
\hline Hinduism & 0.215 & $(0.351)$ & -0.259 & $(0.167)$ & 0.122 & $(0.157)$ \\
\hline Others & 0.560 & $(0.281)$ & 0.047 & $(0.134)$ & 0.072 & $(0.126)$ \\
\hline Married & -0.041 & $(0.093)$ & -0.021 & $(0.045)$ & -0.036 & $(0.042)$ \\
\hline Widowed/ separated/ divorced & 0.002 & $(0.217)$ & 0.037 & $(0.104)$ & -0.170 & $(0.098)$ \\
\hline Education level & 0.077 & $(0.029)$ & -0.046 & $(0.014)^{\mathrm{b}}$ & -0.046 & $(0.013)^{\mathrm{b}}$ \\
\hline House type & 0.092 & $(0.036)$ & -0.030 & $(0.017)$ & -0.042 & $(0.016)$ \\
\hline Household size & -0.018 & $(0.036)$ & 0.011 & $(0.017)$ & 0.013 & $(0.016)$ \\
\hline \multicolumn{7}{|l|}{ Country of birth (base $=$ Singapore) } \\
\hline Others & 0.271 & $(0.108)$ & 0.071 & $(0.051)$ & 0.072 & $(0.048)$ \\
\hline \multicolumn{7}{|l|}{$\begin{array}{l}\text { Lockdown } \\
\text { (base = Lockdown period) }\end{array}$} \\
\hline Before lockdown & -0.437 & $(0.206)$ & -0.017 & $(0.098)$ & 0.075 & $(0.092)$ \\
\hline After lockdown & 1.129 & $(0.263)^{\mathrm{b}}$ & 0.011 & $(0.126)$ & -0.151 & $(0.118)$ \\
\hline $\begin{array}{l}\text { Number of local COVID-19 cases } \\
\text { (log transformed) }\end{array}$ & -0.621 & $(0.173)^{\mathrm{b}}$ & -0.052 & $(0.083)$ & 0.079 & $(0.078)$ \\
\hline$R^{2}$ & & .474 & & 435 & 0.3 & \\
\hline
\end{tabular}

${ }^{a}$ Data reported as beta estimates (standard error)

${ }^{\mathrm{b}}$ Indicates significance at $P<0.002$ (following Bonferroni corrections) 


\section{Strengths}

These study limitations need to be viewed alongside the putative strengths of our research methodology. To the best of our knowledge, our study represents the first attempt to identify individual vulnerabilities in the spread of COVID-19 rumours. The research involved a large sample size (1,237 participants), captured pandemic-related dynamics over a long duration (5 months), and examined specific rumours that had been widely disseminated.

\section{CONCLUSION}

In conclusion, our study revealed that educational level was a protective factor amid an onslaught of COVID-19 rumours. At a time when information regulation is crucial to resilience and well-being, ${ }^{20,39}$ our findings provide a basis to manage the spread of rumours. In other words, it is not apparent that veracity makes a rumour likely to be shared. Instead, COVID-19 rumours are shared even when disbelieved, but may be stemmed through higher education.

\section{Acknowledgements}

This research was funded by a grant awarded from the JY Pillay Global Asia Programme (grant number: IG20-SG002).

\section{REFERENCES}

1. da Silva FCT, Neto MLR. Psychological effects caused by the COVID-19 pandemic in health professionals: A systematic review with meta-analysis. Prog Neuropsychopharmacol Biol Psychiatry 2021;104:110062.

2. Pappa S, Ntella V, Giannakas T, et al. Prevalence of depression, anxiety, and insomnia among healthcare workers during the COVID-19 pandemic: A systematic review and meta-analysis. Brain Behav Immun 2020;88:901-7.

3. Salari N, Hosseinian-Far A, Jalali R, et al. Prevalence of stress, anxiety, depression among the general population during the COVID-19 pandemic: a systematic review and meta-analysis. Glob Health 2020;16:57.

4. Cooke JE, Eirich R, Racine N, et al. Prevalence of posttraumatic and general psychological stress during COVID-19: A rapid review and meta-analysis. Psychiatry Res 2020;292:113347.

5. Torales J, O'Higgins M, Castaldelli-Maia JM, et al. The outbreak of COVID-19 coronavirus and its impact on global mental health. Int J Soc Psychiatry 2020;66:317-20.

6. Gao J, Zheng P, Jia Y, et al. Mental health problems and social media exposure during COVID-19 outbreak. PLoS ONE 2020;15:e0231924. doi:10.1371/journal.pone.0231924

7. Liu JC, Tong EM. The relation between official WhatsAppdistributed COVID-19 news exposure and psychological symptoms: Cross-sectional survey study J Med Internet Res 2020;22:e22142.

8. Vardanjani HM, Heydari ST, Dowran B, et al. A cross-sectional study of Persian medicine and the COVID-19 pandemic in Iran: Rumors and recommendations. Integr Med Res 2020;9:100482.
9. Xiong J, Lipsitz O, Nasri F, et al. Impact of COVID-19 pandemic on mental health in the general population: A systematic review. J Affect Disord 2020;277:55-64.

10. World Health Organization. Novel Coronavirus (2019-NCoV): Situation Report - 13, 2020. Available at: https://www.who.int/docs/ default-source/coronaviruse/situation-reports/20200202-sitrep-13ncov-v3.pdf?sfvrsn=195f4010_6. Accessed on 30 September 2020.

11. Cuan-Baltazar JY, Muñoz-Perez MJ, Robledo-Vega C, et al. Misinformation of COVID-19 on the internet: Infodemiology study. JMIR Public Health Surveill 2020;6:e18444.

12. Hou Z, Du F, Zhou X, et al. Cross-country comparison of public awareness, rumors, and behavioral responses to the COVID-19 epidemic: Infodemiology study. J Med Internet Res 2020;22:e21143.

13. Depoux A, Martin S, Karafillakis E, et al. The pandemic of social media panic travels faster than the COVID-19 outbreak. J Travel Med 2020;27:taaa031.

14. Vosoughi S, Roy D, Aral S. The spread of true and false news online. Science 2018;359:1146-51.

15. Rovetta A, Bhagavathula AS. COVID-19-related web search behaviors and infodemic attitudes in Italy: Infodemiological study. JMIR Public Health Surveill 2020;6:e19374.

16. Singh L, Bansal S, Bode L, et al. A first look at COVID-19 information and misinformation sharing on Twitter, 30 March 2020. Available at: http://arxiv.org/abs/2003.13907 Accessed on 30 September 2020.

17. Abd-Alrazaq A, Alhuwail D, Househ M, et al. Top Concerns of Tweeters During the COVID-19 Pandemic: Infoveillance Study. J Med Internet Res 2020;22:e19016.

18. Ahmed W, Vidal-Alaball J, Downing J, et al. COVID-19 and the 5G Conspiracy Theory: Social Network Analysis of Twitter Data. J Med Internet Res 2020;22:e19458.

19. Aghababaeian H, Hamdanieh L, Ostadtaghizadeh A. Alcohol intake in an attempt to fight COVID-19: A medical myth in Iran. Alcohol 2020;88:29-32.

20. Abdoli A. Gossip, Rumors, and the COVID-19 Crisis. Disaster Med Public Health Prep 2020:14:e29-30.

21. Ebrahim SH, Ahmed QA, Gozzer E, et al. Covid-19 and community mitigation strategies in a pandemic. BMJ 2020:m1066.

22. Holmes EA, O'Connor RC, Perry VH, et al. Multidisciplinary research priorities for the COVID-19 pandemic: a call for action for mental health science. Lancet Psychiatry 2020;7:547-60.

23. Chua AYK, Banerjee S. Intentions to trust and share online health rumors: An experiment with medical professionals. Comput Hum Behav 2018;87:1-9.

24. Banakar M, Sadati AK, Zarei L, et al. Public Sphere Attitudes toward Rumor Sources on COVID-19 Epidemics: Evidence from Community Perceptions in Iran. In Review (Preprint); 2020. doi:10.21203/rs.3.rs-30297/v1

25. Long VJ, Liu JC. Behavioural changes during the COVID-19 pandemic: Results of a national survey in Singapore. medRxiv. doi:10.1101/2020.08.06.20169870

26. Saw YE, Tan EY-Q, Liu JS, et al. Predicting public uptake of digital contact tracing during the COVID-19 pandemic: Results from a nationwide survey in Singapore. J Med Internet Res 2021;23: e24730. doi: $10.2196 / 24730$

27. Ippolito G, Hui DS, Ntoumi F, et al. Toning down the 2019-nCoV media hype-and restoring hope. Lancet Respir Med 2020; $8: 230-1$. 
28. Pew Research Center. News Use across Social Media Platforms 2018. Pew Research Center; 2018.

29. Jin F, Wang W, Zhao L, et al. Misinformation propagation in the age of twitter. Computer 2014;47:90-4.

30. Tran T, Valecha R, Rad P, et al. An Investigation of Misinformation Harms Related to Social Media During Humanitarian Crises. In: Sahay SK, Goel N, Patil V, Jadliwala M, eds. Secure Knowledge Management In Artificial Intelligence Era. Communications in Computer and Information Science. Springer; 2020:167-81.

31. Islam MS, Sarkar T, Khan SH, et al. COVID-19-Related Infodemic and Its Impact on Public Health: A Global Social Media Analysis. Am J Trop Med Hyg 2020;103:1621-9.

32. Wang Y, McKee M, Torbica A, et al. Systematic Literature Review on the Spread of Health-related Misinformation on Social Media. Soc Sci Med 2019;240:112552.

33. Chua AYK, Banerjee S. To share or not to share: The role of epistemic belief in online health rumors. Int J Med Inf 2017;108:36-41.
34. Wong JEL, Leo YS, Tan CC. COVID-19 in Singapore-Current Experience: Critical Global Issues That Require Attention and Action. JAMA 2020;323:1243.

35. Zarocostas J. How to fight an infodemic. The Lancet 2020;395:676.

36. Le HT, Nguyen DN, Beydoun AS, et al. Demand for Health Information on COVID-19 among Vietnamese. Int J Environ Res Public Health 2020;17:4377.

37. Tran BX, Dang AK, Thai PK, et al. Coverage of Health Information by Different Sources in Communities: Implication for COVID-19 Epidemic Response. Int J Environ Res Public Health 2020;17:3577.

38. Chong YY, Cheng HY, Chan HYL, Chien WT, Wong SYS. COVID-19 pandemic, infodemic and the role of eHealth literacy. Int J Nurs Stud 2020;108:103644.

39. Garfin DR, Silver RC, Holman EA. The novel coronavirus (COVID-2019) outbreak: Amplification of public health consequences by media exposure. Health Psychol Off J Div Health Psychol Am Psychol Assoc 2020;39:355-7. 